\title{
Localization and characterization of the ligand- binding domain of the fibrinogen-binding protein (FgBP) of Streptococcus equi subsp. equi
}

\author{
Mary Meehan, ${ }^{1,2}$ Deirdre A. Muldowney, ${ }^{2}$ Naomi J. Watkins ${ }^{2}$ \\ and Peter Owen ${ }^{2}$
}

National Pharmaceutical Biotechnology Centre, BioResearch, Ireland1, and Department of Microbiology, Moyne Institute of Preventive Medicine2, Trinity College, Dublin 2, Ireland
Author for correspondence: Peter Owen. Tel: +353 1 6081188. Fax: +35316799294. e-mail: powen@tcd.ie

The group C streptococcus Streptococcus equi subsp. equi possesses a 498residue major cell-wall-associated protein (FgBP) which binds horse fibrinogen $(F g)$, reacts with convalescent horse serum and protects against lethal $S$. equi challenge in a small animal model. In the present study, analysis of a panel of 17 purified $\mathrm{N}$ - and C-terminal FgBP truncates by ligand affinity blotting and SDS-PAGE revealed that the region required for maximum binding of $\mathbf{F g}$ extended over the first half of the mature protein. The C-terminal two-thirds of this domain is predicted to be $\alpha$-helical coiled-coil and the $\mathbf{N}$-terminal onethird to possess non-coiled-coil single strands. Residues at the extreme $\mathbf{N}$ terminus and within the coiled-coil region are both required for ligand binding. A high incidence of $\alpha$-helical coiled-coil structure also seems to be responsible in part for the aberrant mobility of FgBP on SDS gels. The efficiency with which FgBP binds Fg from different animal species decreases in the order horse $>$ mouse, pig $>$ rat $>$ sheep, dog, bovine, human. Binding to horse $\mathrm{Fg}$ is inversely related to temperature over the range $45-4{ }^{\circ} \mathrm{C}$ and is independent of $\mathrm{Ca}^{2+}$ ions. MS analysis provided corroborative evidence that FgBP is covalently linked to the cell wall peptidoglycan.

Keywords: Streptococcus equi subsp. equi, fibrinogen-binding protein, ligand-binding domain

\section{INTRODUCTION}

Fibrinogen (Fg) is a major component of plasma, and the ability to bind $\mathrm{Fg}$ is common amongst cell wall proteins of pathogenic Gram-positive bacteria (Kehoe, 1994; Patti et al., 1994). Fg consists of three pairs of nonidentical chains $(\alpha, \beta, \gamma)$ linked by disulphide bonds and has an $M_{\mathrm{r}}$ of 340000 . For the host, Fg has two main functions: polymerization into fibrin and mediation of platelet aggregation. Together, these result in the formation of platelet-fibrin thrombi (Doolittle, 1994). In Gram-positive bacteria, Fg binds to the variable Nterminal/central regions of many cell-wall-associated proteins, an interaction which appears to serve several different functions. For example, although the precise

Abbreviations: $C D$, circular dichroism; Fg, fibrinogen; FgBP, fibrinogenbinding protein; MALDI-TOF, matrix-assisted laser desorption/ionization time-of-flight. mechanism by which streptococci resist phagocytosis remains controversial, Fg binding to $M$ protein does appear to play a role in resistance to phagocytosis for several strains of Streptococcus pyogenes (Courtney et al., 1997; Kehoe, 1994; Navarre \& Schneewind, 1999; Poirier et al., 1989; Whitnack \& Beachey, 1982, 1985). On the other hand, Fg binding to Staphylococcus aureus has been shown to be important in the initiation of infections of implanted medical devices and surgical wounds by promoting bacterial attachment (Herrmann et al., 1993; Moreillon et al., 1995; Vaudaux et al., 1989, 1995).

Streptococcus equi subsp. equi, a group C streptococcus, is the causative agent of strangles, a highly contagious and debilitating upper respiratory tract disease of the family Equidae. The disease is initially characterized by nasal discharge and fever followed by swelling and abscess formation in local lymph nodes (Timoney, 1993). In a recent publication, we described the puri- 
fication of a fibrinogen-binding protein (termed FgBP) from the cell wall of $S$. equi subsp. equi. FgBP was shown to have an apparent $M_{\mathrm{r}} 220000$ when analysed by SDS-PAGE, reacted with convalescent horse serum and was protective in a small animal model against lethal $S$. equi challenge (Meehan et al., 1998a). The sequence of the corresponding gene $(f b p)$ was determined and was shown to encode a protein of 534 amino acids $\left(M_{\mathrm{r}}\right.$ 58344 ) which possessed some structural and sequence similarities to other streptococcal cell wall proteins. Of note were characteristic signal sequence and cell wall/ membrane-spanning domains, two blocks (A and B) of degenerate repeated sequences and a high probability of $\alpha$-helical coiled-coil structure over about $60 \%$ of the molecule. The sequence was identical, with the exception of six amino acids, to the M-like protein (SeM) described by Timoney et al. (1997) for a different isolate of $S$. equi subsp. equi. There is evidence to suggest that, like streptococcal $\mathrm{M}$ proteins, $\mathrm{FgBP}(\mathrm{SeM})$ is antiphagocytic by limiting $\mathrm{C} 3 \mathrm{~b}$ deposition on the bacterial cell surface, that antiserum to the protein is opsonic and that Fg binding may enhance the ability of S. equi subsp. equi to resist killing by equine neutrophils (Boschwitz \& Timoney, 1994a, b; Timoney et al., 1997).

Previously, we described the overexpression and purification of a recombinant FgBP truncate which lacked the signal sequence and C-terminal cell wall/membrane domain and showed that this recombinant protein behaved in an analogous fashion to wild-type FgBP in terms of $\mathrm{Fg}$ binding, seroreactivity and protective immunogenic potential (Meehan et al., 1998a, b). In the present communication, we describe the construction of a panel of FgBP truncates, show that the Fg-binding domain is localized in the N-terminal region of mature $\mathrm{FgBP}$, and that the efficiency of Fg binding is dependent on temperature and source of $\mathrm{Fg}$. We also provide evidence from MS analysis of recombinant and wildtype $\mathrm{FgBP}$ that the native protein may be covalently linked at its C-terminus to the streptococcal cell wall.

\section{METHODS}

Bacterial strains, plasmids and growth conditions. Escherichia coli XL-1 Blue (Stratagene) and plasmid pQE30 (Qiagen) were used for expression of the recombinant FgBP proteins. The virulent isolate, strain TW, of S. equi subsp. equi was obtained from the late Dr Paul Storm of Intervet International BV, The Netherlands (Meehan et al., 1998a). E. coli strains were grown at $37^{\circ} \mathrm{C}$ in either LB medium or $2 \times$ YT medium (Lech \& Brent, 1997). Where appropriate, media were supplemented with ampicillin $\left(100 \mu \mathrm{g} \mathrm{ml}^{-1}\right)$ and IPTG $(1 \mathrm{mM})$. S. equi subsp. equi was grown at $37^{\circ} \mathrm{C}$ on Columbia base agar supplemented with $5 \%(\mathrm{v} / \mathrm{v})$ horse blood or statically overnight in Todd-Hewitt broth supplemented with $0 \cdot 2 \%(\mathrm{w} / \mathrm{v})$ yeast extract.

Recombinant DNA techniques. Genomic DNA was isolated from $S$. equi TW by a modification of the method of Yu \& Ferretti (1989) as described previously (Meehan et al., 1998a). Plasmid DNA was purified from E. coli by a modified alkaline lysis method (Feliciello \& Chinali, 1993). DNA restriction digestions, ligations and transformations were carried out by standard methods (Sambrook et al., 1989).
Biochemical procedures. SDS-PAGE was performed using either $12.5 \%(\mathrm{w} / \mathrm{v})$ or $7.5 \%(\mathrm{w} / \mathrm{v})$ polyacrylamide separating gels and a $4.5 \%(\mathrm{w} / \mathrm{v})$ polyacrylamide stacking gel (Laemmli, 1970). Samples were routinely heated for $3 \mathrm{~min}$ at $100^{\circ} \mathrm{C}$ in Laemmli sample buffer (Laemmli, 1970) prior to electrophoresis. Proteins were detected by staining with Coomassie brilliant blue. $M_{\mathrm{r}}$ values were determined from the relative mobilities of 15 standard marker proteins (Gibco-BRL; BenchMark protein ladder).

Protein concentration was estimated by a modification (Dulley \& Grieve, 1975) of the Lowry method using BSA as standard. Matrix-assisted laser desorption/ionization time-of-flight (MALDI-TOF) MS was performed as follows by Dr Len C. Packman, Dept Biochemistry, Cambridge, UK. FgBP samples $(0.5 \mu \mathrm{l})$ dissolved in dilute $(10-50 \mathrm{mM})$ sodium phosphate buffer $(\mathrm{pH} 7 \cdot 2)$ or $0 \cdot 1 \%(\mathrm{v} / \mathrm{v})$ trifluoroacetic acid $/ 50 \%(\mathrm{v} / \mathrm{v})$ acetonitrile were mixed with $0.5 \mu \mathrm{l}$ matrix solution [sinapinic acid $\left(10 \mathrm{mg} \mathrm{ml}^{-1}\right)$ in $50 \%(\mathrm{v} / \mathrm{v})$ acetonitrile containing $0.1 \%$ $(\mathrm{v} / \mathrm{v})$ trifluoroacetic acid] and dried onto sample slides at $25-30{ }^{\circ} \mathrm{C}$ in a fan-ventilated drying box. Samples were washed twice with $4 \mu \mathrm{l}$ water to remove salts, then dried, and a further $0.5 \mu \mathrm{l}$ matrix was added. As necessary to improve the signal, samples were rewashed and further matrix solution was applied. An empirical dilution series of the protein sample (5-50-fold) was tested to ascertain the sample conditions necessary to give the optimal mass spectral signal. Mass analysis was carried out on a Kratos MALDI 4 time-of-flight mass spectrometer following the manufacturer's recommendations. Masses were determined using rabbit aldolase $\left(M_{\mathrm{r}}\right.$ 39211) and horse myoglobin $\left(M_{\mathrm{r}} 16951\right)$ as internal calibrants. Errors were minimized by averaging at least five mass determinations.

Immunological and affinity procedures. Western immunoblotting was performed as described previously (Caffrey et al., $1988)$ using $5 \%(\mathrm{w} / \mathrm{v})$ dried skimmed milk as blocking reagent and rabbit anti-FgBP (1:10000 dilution; Meehan et al., 1998a). Affinity-purified horseradish-peroxidase-labelled goat antirabbit IgG $\mathrm{H}+\mathrm{L}(\mathrm{ICN})$ was used as localizing antibody and 4chloro-1-naphthol as developing reagent. The procedure for Fg-affinity blotting after electrotransfer from SDS-PAGE was as described by Meehan et al. (1998a). For dot Fg-affinity blots, solutions containing FgBP truncates were subjected to doubling dilutions and $150 \mu \mathrm{l}$ aliquots (containing 100$0.05 \mathrm{pmol}$ ) were transferred onto nitrocellulose using the BioRad Bio-Dot apparatus. After the blots had dried, they were blocked, incubated with labelled horse Fg and developed as described for Fg-affinity electroblots (Meehan et al., 1998a).

ELISA tests were carried out using standard procedures (Newell et al., 1988). For analysis of FgBP binding to Fgs from different animal species, wells of microtitre plates were coated overnight with $50 \mu \mathrm{l} \mathrm{Fg}$ solutions, ranging in concentration from 10 to $0 \cdot 0195 \mu \mathrm{g}$ per $\mathrm{ml} 0 \cdot 1 \mathrm{M}$ sodium carbonate buffer ( $\mathrm{pH} 9.6)$. Wells were blocked with $4 \%(\mathrm{w} / \mathrm{v})$ dried skimmed milk, incubated with FgBP $\left(1.25 \mu \mathrm{g} \mathrm{ml}^{-1}\right)$, followed by rabbit anti-FgBP antibodies (1:5000 dilution) and peroxidaselabelled anti-rabbit IgG (1:5000 dilution; ICN). For analysis of Fg binding at different temperatures and to determine the concentration of ligand resulting in $50 \%$ saturation of receptor, wells were coated with $25 \mathrm{ng}$ FgBP1, blocked with $1 \%(\mathrm{w} / \mathrm{v})$ BSA and probed with doubling dilutions of horseradish-peroxidase-labelled horse/human Fg as appropriate. For these experiments, blocking was performed in two stages: (1) incubation at $22{ }^{\circ} \mathrm{C}$ for $30 \mathrm{~min}$ followed by (2) incubation for $30 \mathrm{~min}$ at one of several temperatures $(4,22$, 30,37 or $45^{\circ} \mathrm{C}$ ). Subsequent washing and incubation steps were carried out at the chosen temperature. All ELISA tests 

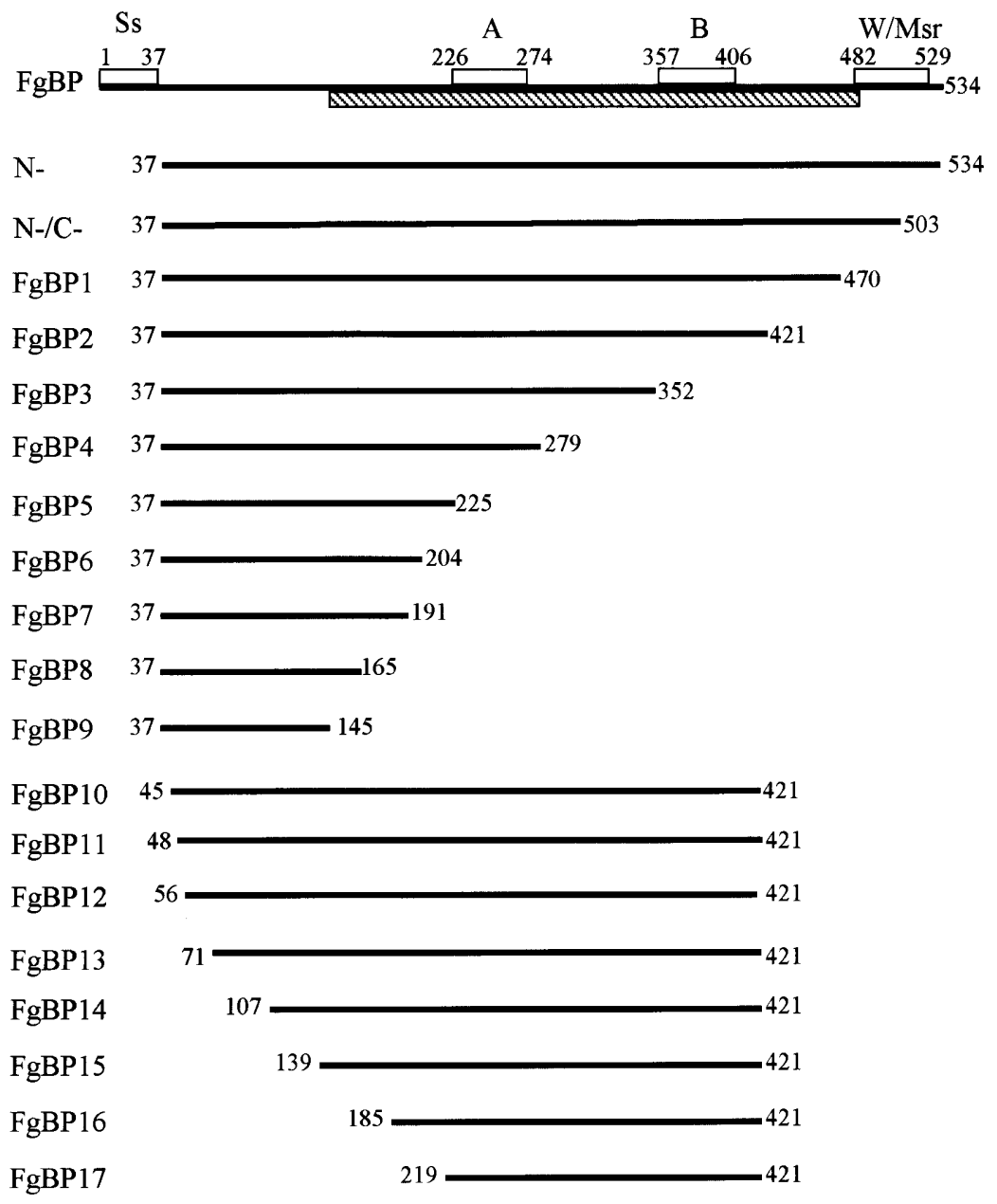

Fig. 1. Schematic representation of $S$. equi $\mathrm{FgBP}$ and of recombinant FgBP truncates. The upper part of the figure represents the primary structure of FgBP. Open boxes represent the positions of the signal sequence (Ss), the $A$ and $B$ repeats and the wall- and membrane-spanning regions (W/Msr). The lower striped box represents the region of FgBP predicted to have $50-100 \%$ probability of possessing an $\alpha$ helical coiled-coil structure. Below the primary structure of FgBP are scaled representations of $\mathrm{N}$-terminally processed FgBP $\left(\mathrm{N}_{37}-\mathrm{N}_{534}\right)$, S. equi FgBP after processing at both its $\mathrm{N}$ - and C-termini $\left(\mathrm{N}_{37}-\mathrm{T}_{503}\right)$ and a panel of 17 recombinant FgBP truncates (FgBP1-17) overexpressed in E. coli. were developed at room temperature using 3,3',5,5'-tetramethylbenzidine as substrate and the $A_{450}$ was measured.

Purification of FgBP. FgBP was purified from $S$. equi as described previously (Meehan et al., 1998a). Briefly, this involved lysis of $S$. equi cells by passage through a French pressure cell $(221 \mathrm{MPa})$ and harvesting of cell envelopes by centrifugation $\left(45000 \mathrm{~g}, 1 \mathrm{~h}, 4^{\circ} \mathrm{C}\right)$. Cell envelopes were then digested overnight with mutanolysin $\left(800 \mathrm{U} \mathrm{ml}^{-1}\right)$ in the presence of a cocktail of protease inhibitors. Following centrifugation $\left(45000 \mathrm{~g}, 1 \mathrm{~h}, 4^{\circ} \mathrm{C}\right)$, proteins, including $\mathrm{FgBP}$, which were released from the cell wall were recovered in the supernatant fraction. FgBP was then purified from this preparation by horse Fg-affinity chromatography (Meehan et al., 1998a).

Expression and purification of FgBP truncates. Oligonucleotide primers (Genosys) complementary to selected $f b p$ sequence were used to amplify $f b p$ fragments. Restriction enzyme cleavage sites (BamHI or XmaI) were engineered into the $5^{\prime}$ end of all primers. A stop codon was also engineered directly after the restriction enzyme cleavage site at the $5^{\prime}$ end of reverse primers. One hundred microlitre PCR reactions were performed in cloned $p f u$ polymerase buffer (Stratagene) containing $5 \mathrm{U}$ cloned $p f u$ polymerase, $250 \mathrm{ng}$ forward and reverse primers, $250 \mu \mathrm{M}$ dNTPs and $100 \mathrm{ng}$ pFP21 (recombinant pQE30 which expresses truncate FgBP1) or $500 \mathrm{ng} S$. equi genomic DNA. Amplification conditions consisted of 30 cycles of denaturation at $94^{\circ} \mathrm{C}$ for $1 \mathrm{~min}$, annealing at $55^{\circ} \mathrm{C}$ for $1 \mathrm{~min}$ and extension at $72^{\circ} \mathrm{C}$ for $2 \mathrm{~min} / 1 \mathrm{~kb}$ of product followed by a final extension at $72{ }^{\circ} \mathrm{C}$ for $10 \mathrm{~min}$. DNA was then purified using Wizard PCR preps (Promega), cleaved with appropriate restriction enzymes and cloned into pQE30. Recombinant plasmids were transformed into E. coli XL-1 Blue.

Hexahistidyl-tagged FgBP truncates were purified by metal chelate affinity chromatography using a modification of the method described by Meehan et al. (1998a). E. coli containing the recombinant $\mathrm{pQE} 30$ plasmids was grown, harvested and lysed by passage through a French pressure cell $(221 \mathrm{MPa})$ as previously described. The soluble cytoplasmic/periplasmic fraction was applied to a nickel-iminodiacetic acid column, which was then washed extensively with binding buffer containing $40 \mathrm{mM}$ imidazole until the $A_{280}$ of the effluent reached zero. Hexahistidyl-tagged $\mathrm{FgBP}$ truncates were recovered using an $80-400 \mathrm{mM}$ gradient of imidazole in binding buffer. Most of the purified proteins were then extensively dialysed against several changes of $50 \mathrm{mM}$ sodium phosphate $(\mathrm{pH} 7 \cdot 2)$ containing decreasing concentrations $(0 \cdot 5$, 0.2 and $0.1 \mathrm{M}$ ) of $\mathrm{NaCl}$. Some of the smaller truncates tended to precipitate at lower $\mathrm{NaCl}$ concentrations. Accordingly, these were ultimately dialysed against either $0.2 \mathrm{M} \mathrm{NaCl}$ (FgBP6-8) or 0.5 M NaCl (FgBP9). Where necessary, purified proteins were concentrated by ultrafiltration using an Amicon PM10 filter. 


\section{RESULTS}

\section{Localization of the Fg-binding domain}

In order to localize the Fg-binding domain of FgBP, DNA fragments of $f b p$ were amplified by PCR and cloned in-frame into the expression vector $\mathrm{pQE} 30$. The resultant recombinant FgBP proteins (FgBP1-17; Fig. 1) were purified by metal chelate chromatography in the presence of protease inhibitors and analysed by SDSPAGE (Fig. 2). The panel of recombinant molecules so constructed covered truncates lacking the wall/ membrane anchor domain (FgBP1), ones lacking the wall/membrane anchor domain and increasing amounts of the putative coiled-coil domain (which includes the A and $\mathrm{B}$ repeat regions; FgBP2-9), together with ones lacking the wall/membrane anchor domain and an increasing number of N-terminal residues (FgBP10-17). All purified truncates gave a single dominant band following SDS-PAGE, with the exception of FgBP3, which routinely purified as two components (FgBP3a

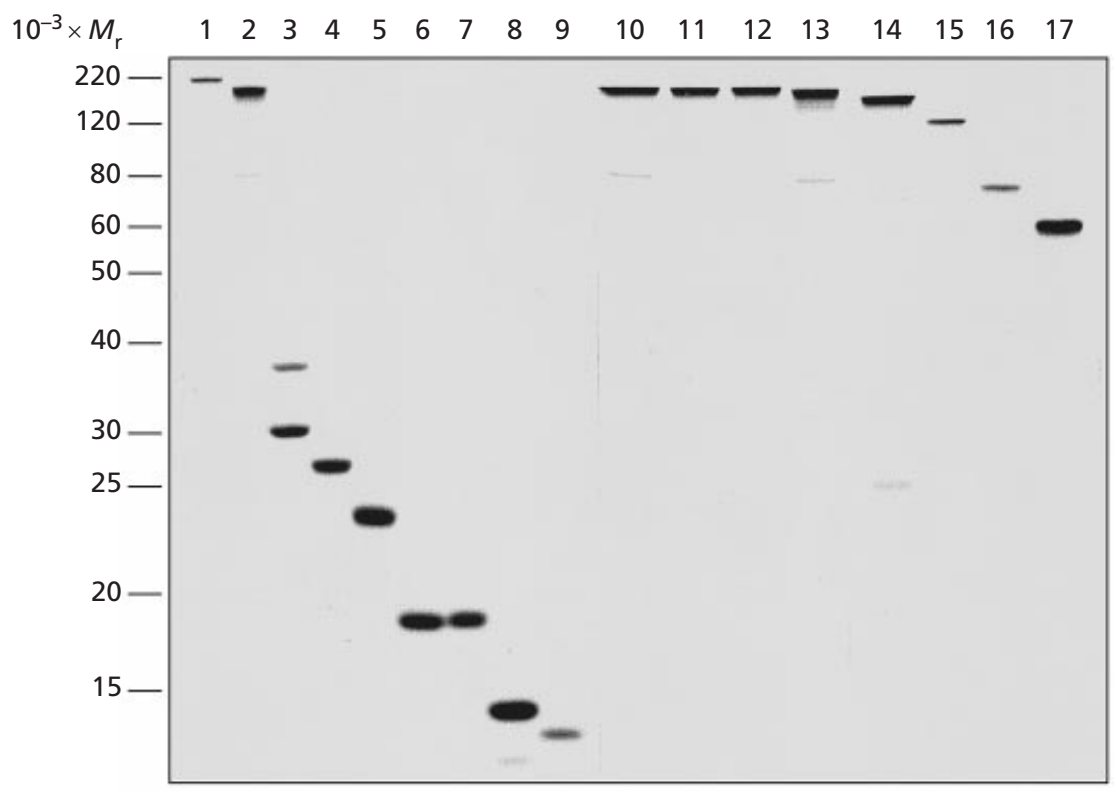

Fig. 2. SDS-PAGE of purified hexahistidyltagged FgBP truncates. Lanes 1-17, FgBP truncate numbers 1-17, respectively (see Fig. 1). Proteins have been stained with Coomassie brilliant blue, and the positions and $M_{\mathrm{r}}$ values of marker proteins are indicated to the left.

Table 1. $M_{\mathrm{r}}$ values and predicted coiled-coil structure of FgBP truncates

\begin{tabular}{|lccc|}
\hline FgBP truncate & $\begin{array}{c}\text { Loss of coiled-coil } \\
\text { structure }(\%)\end{array}$ & $\begin{array}{c}\boldsymbol{M}_{\mathrm{r}} \text { predicted from } \\
\text { sequence }\end{array}$ & $\begin{array}{c}\boldsymbol{M}_{\mathrm{r}} \text { estimated by } \\
\text { SDS-PAGE }\end{array}$ \\
\hline Native FgBP & 0 & 52486 & 220000 \\
FgBP1 & 4 & 49541 & 200000 \\
FgBP2 & 18 & 43861 & 190000 \\
FgBP3a & 39 & 36317 & 35500 \\
FgBP3b & 48 & $33111^{*}$ & 29500 \\
FgBP4 & 60 & 28434 & 27500 \\
FgBP5 & 76 & 22841 & 23000 \\
FgBP6 & 83 & 20377 & 16500 \\
FgBP7 & 85 & 18868 & 17000 \\
FgBP8 & 94 & 15758 & 13500 \\
FgBP9 & 100 & 13420 & 12000 \\
FgBP10 & 18 & 42915 & 185000 \\
FgBP11 & 18 & 42549 & 185000 \\
FgBP12 & 18 & 41679 & 185000 \\
FgBP13 & 18 & 40121 & 170000 \\
FgBP14 & 18 & 36201 & 155000 \\
FgBP15 & 18 & 32538 & 110000 \\
FgBP16 & 30 & 27224 & 75000 \\
FgBP17 & 40 & 23110 & 60000 \\
\hline
\end{tabular}

*Estimated by MALDI-TOF MS. 


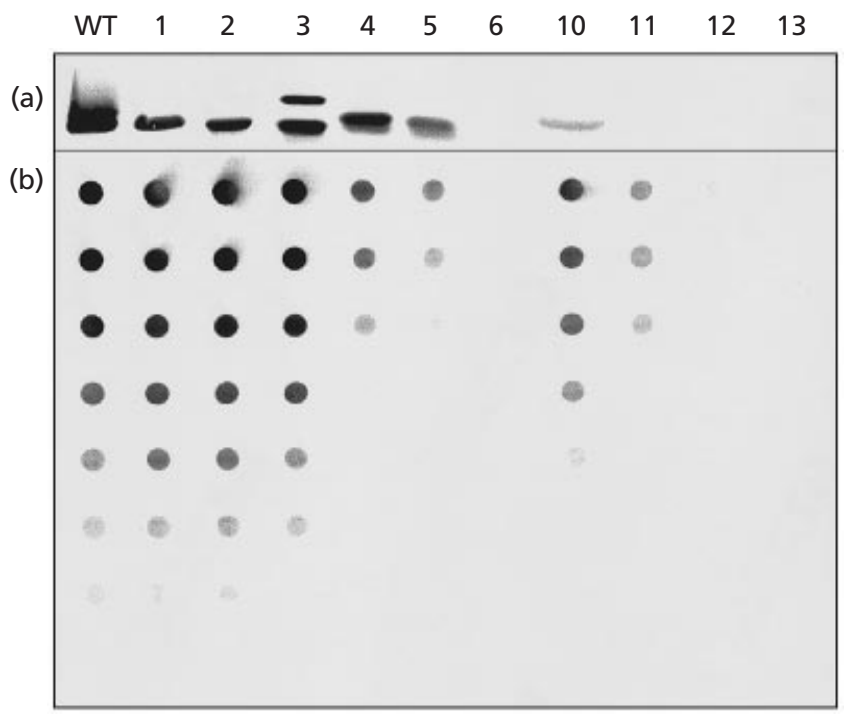

Fig. 3. Fg-affinity blot analysis of FgBP truncates. (a) Reactions obtained following SDS-PAGE and Western affinity blotting of samples depicted in Fig. 2. Only the regions of the blot containing the various FgBP truncates are shown. (b) Affinity dot blot performed with undenatured FgBP truncates. The top (initial) well in each column of doubling dilutions contains $33 \mathrm{pmol}$ truncate. Sample identity is indicated at the top. FgBP7-9 and FgBP14-17 give identical profiles following dot blotting to that shown for FgBP13.

and FgBP3b; see Fig. 2 and Table 1). MS, nucleotide sequencing and affinity binding data confirmed that the lower- $M_{\mathrm{r}}$ species $(\mathrm{FgBP} 3 \mathrm{~b}$ ) was a degradation product lacking a further 30 amino acids from its $\mathrm{C}$-terminus.

All purified truncates (including both FgBP3a and $3 \mathrm{~b}$ ) reacted with anti-FgBP antibodies as assessed by both Western and dot immunoblotting (data not shown). However, only the native protein and FgBP truncates 1, 2, 3a, 3b, 4, 5 and 10 bound detectable levels of Fg in corresponding Western affinity blotting experiments (see Fig. 3a). To place these observations on a more quantitative basis and to obviate demonstrable problems associated with SDS-induced reduction in Fg binding during SDS-PAGE and with less efficient electrotransfer of more tightly focused high- $M_{\mathrm{r}}$ truncates, dot-blotting experiments were performed using undenatured FgBPs (Fig. 3b). These semi-quantitative experiments confirmed the general trend observed during Western affinity blotting and revealed that in the absence of SDS (a) wild-type FgBP, FgBP1 (which lacks the wall/ membrane anchor domain) and FgBP2-3a/3b (missing 113 and 182/212 amino acids from their C-termini, respectively) all bound similar levels of $\mathrm{Fg}$ to a first approximation, (b) FgBP4-6 (missing 255, 309 and 330 C-terminal residues, respectively) bound approximately 16-, 32- and 128-fold less Fg than FgBP1, (c) N-terminal truncates FgBP10-12 (which have 8, 11 and 19 residues, respectively, deleted from their $\mathrm{N}$-termini) bound about 4-, 16- and 128-fold less Fg than their FgBP2 control and (d) the remaining truncates, i.e. FgBP7-9 and FgBP13-17 (see Fig. 1), bound no detectable Fg (Fig. 3b).
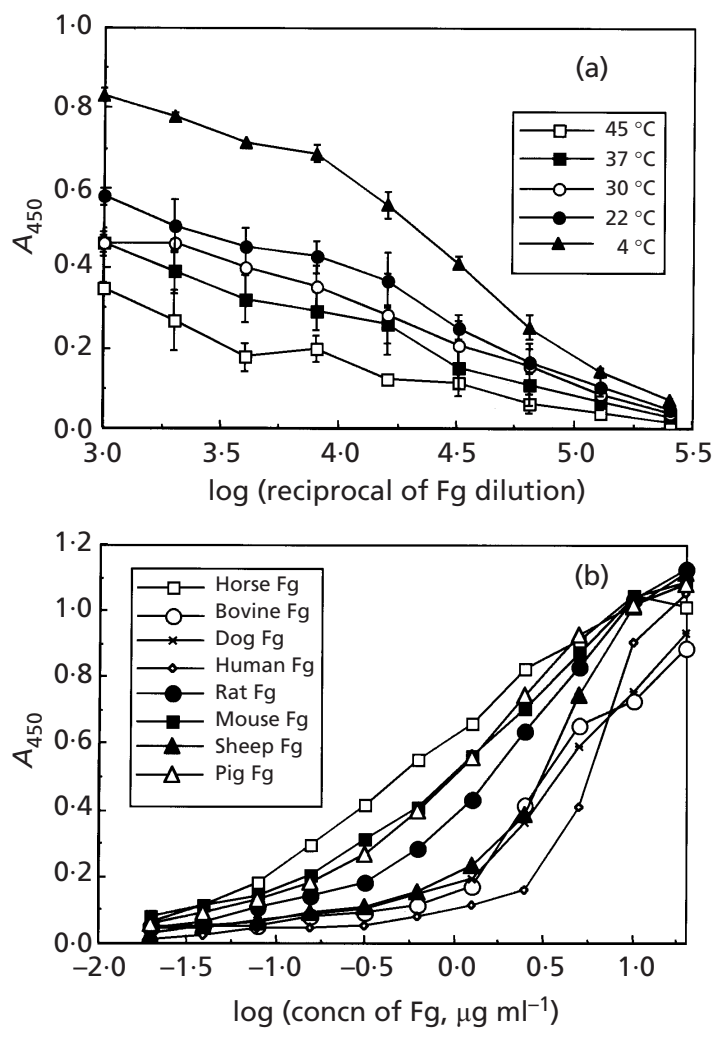

Fig. 4. Efficiency of FgBP1 binding to (a) horse Fg at different temperatures and (b) Fgs from different mammals. For clarity, error bars have been omitted from (b).

\section{Effect of $\mathrm{Ca}^{2+}$, temperature and $\mathrm{Fg}$ type on $\mathrm{Fg}$ binding}

$\mathrm{Ca}^{2+}$ has recently been shown to play a regulatory role in the interaction of $\mathrm{Fg}$ with several staphylococcal $\mathrm{Fg}$ binding proteins, e.g. ClfA, ClfB and Efb (Ní Eidhin et al., 1998; O'Connell et al., 1998; Palma et al., 1998). However, this does not appear to be the case for S. equi subsp. equi since preincubation of $\mathrm{FgBP}$ with a range of concentrations (in twofold dilutions) of $\mathrm{Ca}^{2+}$ (50-0.24 mM), EDTA $(20-0 \cdot 01 \mathrm{mM})$ or EGTA (20$0.01 \mathrm{mM}$ ) did not alter Fg binding to immobilized FgBP in ELISA tests (data not shown). Nor did the sequence of FgBP show the presence of a potential cation-binding EF-hand-like motif reportedly implicated in the binding of Fg to staphylococcal ClfA and ClfB proteins (Meehan et al., 1998a; Ní Eidhin et al., 1998; O’Connell et al., 1998). In contrast, temperature did affect Fg binding to FgBP1 (and to other smaller Fg-binding FgBP truncates), the binding being significantly more efficient at $4{ }^{\circ} \mathrm{C}$ than at $37^{\circ} \mathrm{C}$ (see Fig. 4a). Other assays performed with Fgs from a number of different mammals (see Fig. 4b) showed that FgBP bound the various molecules with the following approximate efficiencies with regard to horse $\mathrm{Fg}$ : viz. mouse and pig Fg, $50 \%$; rat Fg, $25 \%$; sheep, dog, bovine and human Fg, 3-8\%. Additional ELISA experiments (not shown) revealed that (a) the concentrations of horse and human Fg resulting in $50 \%$ 
saturation of receptor at $4{ }^{\circ} \mathrm{C}$ were $40 \mathrm{ng} \mathrm{ml}^{-1}$ and $320 \mathrm{ng} \mathrm{ml}^{-1}$, respectively, and (b) at $45^{\circ} \mathrm{C}$, an approximately ninefold higher concentration of horse Fg was required to cause $50 \%$ saturation of receptor than at $4{ }^{\circ} \mathrm{C}$.

\section{Aberrant mobility during SDS-PAGE}

Previous studies had shown that the $M_{\mathrm{r}}$ values of native $\mathrm{FgBP}$ and recombinant FgBP1 as estimated by SDSPAGE (220000 and 200000, respectively) were greatly at variance with those $\left(M_{\mathrm{r}} 54597\right.$ and 49541, respectively) predicted from consideration of gene sequence (Meehan et al., 1998a). SDS-PAGE analysis of the current panel of $\mathrm{FgBP}$ truncates provides evidence that a high incidence of $\alpha$-helical coiled-coil structure may be responsible in part for this phenomenon (Table 1). Thus removal of residues from the $\mathrm{N}$-terminus of the protein where there is a low probability of $\alpha$-helical coiled-coil structure and/or removal from the C-terminus of residues accounting for about $18 \%$ of the total coiled-coil structure generated truncates (FgBP1, 2, 10-15) in which the dominant protein species showed an apparent: predicted $M_{\mathrm{r}}$ ratio (4-4.3) almost identical to that observed for wild-type FgBP. Removal of a further $12-22 \%$ of predicted coiled-coil structure from the $\mathrm{N}$-terminus caused resultant truncates (FgBP16-17) to migrate with an apparent $M_{\mathrm{r}}$ about $2 \cdot 6-2 \cdot 8$ times that predicted, whereas removal of $39 \%$ or more of predicted coiledcoil structure from the C-terminus caused truncates (FgBP3-9) to migrate on SDS gels with an estimated $M_{r}$ close to that predicted from a consideration of sequence (see Table 1). Thus it would appear that (a) various $\mathrm{FgBP}$ truncates have the ability to migrate as apparent tetramers, trimers/dimers or monomers during SDSPAGE and (b) this phenomenon can be correlated, at least in part, with the extent of predicted coiled-coil structure in the molecule. Whether these observations have any bearing on the macromolecular structure of FgBP in situ remains to be determined (see Meehan et al., 1998a, for further discussion of this issue).

\section{Wall association of $\mathrm{FgBP}$}

Several lines of evidence strongly support the view that $\mathrm{FgBP}$ is covalently linked to peptidoglycan in situ. Firstly, it can only be released from the purified cell walls following digestion of the latter with the muralytic enzyme mutanolysin. Secondly, it possesses an LPSTG cell-wall sorting sequence (Meehan et al., 1998a). In staphylococci, there is formal evidence that such sequences are proteolytically cleaved and that a new amide bond is formed between Thr of the sorting sequence and the uncross-linked peptide crossbridge of peptidoglycan (Navarre \& Schneewind, 1999; TonThat et al., 1997). Finally and importantly, MALDITOF MS analysis of wild-type FgBP (purified following mutanolysin digestion) supports this general scenario. Thus the $M_{\mathrm{r}}$ of FgBP1 estimated by mass spectrometry $\left(M_{\mathrm{r}} 49540 \pm 22\right)$ was in excellent agreement with that predicted from consideration of sequence (49541). However, the estimated $M_{\mathrm{r}}$ of wild-type FgBP purified following mutanolysin digestion of the cell wall was determined to be $52440 \pm 90$. This is at considerable variance with that predicted for the primary translation product after $\mathrm{N}$-terminal processing of the signal sequence at $\mathrm{N}_{37}\left(M_{\mathrm{r}}\right.$ 54597; Meehan et al., 1998a) or after additional C-terminal processing at $\mathrm{T}_{503}$ in the cell wall sorting motif $\left(M_{\mathrm{r}}\right.$ 51467). On the other hand, it is consistent with a FgBP molecule (predicted $M_{\mathrm{r}} 52486$ ) which had been processed at both its $\mathrm{N}$ - and C-termini (i.e. $\mathrm{N}_{37}-\mathrm{T}_{503}$ ) and amide-linked at $\mathrm{T}_{503}$ to the dialanyl crossbridge of the putative murein subunit AAK(A)QAMurNAcGlcNAc (Schleifer \& Kandler, 1972). However, additional experimentation is required to formally prove this point.

\section{DISCUSSION}

Analysis of overlapping truncates has succeeded in defining for the first time the region within S. equi FgBP required for $\mathrm{Fg}$ binding. Maximum ligand binding requires a considerable proportion (about 52-68\%) of the native (wall-associated) protein, and involves a region extending from the vicinity of the $\mathrm{N}$-terminus (residue 37) to beyond residue 279, possibly as far as about residue 352. Within this domain, individual residues at the $\mathrm{N}$-terminus appear to be more crucial to Fg-binding activity than those positioned at the Cterminus. Thus removal of as few as 19 residues from the $\mathrm{N}$-terminus results in dramatic (over 128-fold) loss of binding activity, whereas similar loss of Fg binding is only evidenced after the removal of about 150 residues from the C-terminal aspect of this (316-residue) domain. The presence in the various truncates of the $\mathrm{N}$-terminal hexahistidyl affinity tag did not itself appear to compromise ligand binding as evidenced by the similarity in $\mathrm{Fg}$ binding efficiencies of wild-type FgBP and recombinant derivatives such as FgBP1-3.

An $\mathrm{N}$-terminal localization of $\mathrm{Fg}$ binding for $\mathrm{FgBP}$ is reminiscent of the reported binding of Fg to other streptococcal proteins such as the $\mathrm{M}$ proteins of serotypes 1, 3 and 5, and the FAI protein. However, sequence comparison of the relevant domains of these and other similar proteins has failed to reveal any regions of significant homology or recognized motif structures. It seems that $\mathrm{Fg}$ is capable of binding to some of the most variable regions of these proteins (Akesson et al., 1994; Kehoe, 1994; Reichardt et al., 1997; Talay et al., 1996). In these respects, the mechanism of Fg binding to $S$. equi FgBP is clearly distinct from that displayed by the staphylococcal Fg-binding proteins ClfA, ClfB and Efb. These latter proteins have been shown to bind preferentially to one or more of the three Fg chains in a manner which probably involves $\mathrm{Ca}^{2+}$ ions and a cation-binding EF-hand-like motif (McDevitt et al., 1997; Meehan et al., 1998a; Ní Eidhin et al., 1998; O’Connell et al., 1998; Palma et al., 1998).

Of probable relevance to the mechanism of Fg binding 
are computer predictions of structure. These suggest that (a) residues $37-45$ at the extreme N-terminus of wild-type FgBP (and FgBP1-9) exist in a random coil structure, whilst the balance of the molecule is largely (over $84 \%$ ) $\alpha$-helical; and (b) $60 \%$ of the mature protein (from residues 166 to 475 of the precursor protein) possesses an extremely high probability $(95-100 \%)$ of $\alpha$ helical coiled-coil structure, with zero to very low probability of such structures in the first 110 residues (residues 37-147; Meehan et al., 1998a). Ongoing structural studies of key $\mathrm{FgBP}$ truncates by circular dichroism (CD) have confirmed many of these predictions. Thus FgBP1 shows almost $100 \% \alpha$-helical content by $\mathrm{CD}$ using the CONTIN secondary structure estimation procedure (Provencher \& Glockner, 1981), and shows a molar ellipticity $\left(\left[\theta_{222}\right] /\left[\theta_{208 \cdot 6}\right]=1 \cdot 06\right)$ similar to that observed for other coiled coils ( $M$. Meehan and others, unpublished data). Based on these observations and the ligand-binding profiles detailed above, it is tempting to envisage critical Fg-binding domain(s) located in the less structured non-coiled-coil $\mathrm{N}$-terminal aspect of the FgBP dimer, with $\alpha$-helical coiled-coil sequences to the flanking (C-terminal) side providing, in part, a stabilizing structure which anchors and places constraints on the relative positioning of the non-coiled-coil single strands. In this model, excessive C-terminal truncation might serve to alter the gross structure of the FgBP molecule, either prior to or following interaction with its macromolecular ligand, leading to loss of effective interaction with Fg. Alternatively, Fg might interact with both the $\mathrm{N}$-terminal and coiled-coil aspects of FgBP. Indeed, the coiled-coil region apparently necessary for full Fg binding (approx. 27 heptads, or 52 helical turns) is substantially greater than the minimum length generally considered necessary for the formation and stabilization of coiled-coil structures (three to four heptads; Su et al., 1994; Lau et al., 1984). Perhaps, as has been suggested for other systems, the coiled-coil structure of FgBP interacts in zipper-like fashion with the coiled-coil structure of Fg (Åkesson et al., 1994; Kehoe, 1994; Reichardt et al., 1997). This might serve to facilitate/stabilize interactions at the distal $\mathrm{N}$-terminal site (or vice versa) and enhance binding efficiency. Both A and B repeated sequences of $S$. equi $\mathrm{FgBP}$ are present in the region of predicted coiled-coil structure (see Fig. 1). Of these, the degenerate B repeats are unlikely to be involved in binding since they are absent in truncate $\mathrm{FgBP} 3$, which displays wild-type Fgbinding efficiency. In contrast, the A repeats are clearly positioned within the region of the molecule required for full $\mathrm{Fg}$ binding. However, the A repeats are neither essential nor sufficient for $\mathrm{Fg}$ binding since they are absent in FgBP5, which still retains some, albeit weak, binding activity and are present in truncates (FgBP1316) which are devoid of detectable activity. Whatever the precise mechanisms involved, it would appear that sites at the immediate $\mathrm{N}$-terminus of $\mathrm{FgBP}$ and an extended region within the coiled-coil section of the molecule are both required for optimum Fg-binding activity. Biophysical studies should allow more critical appraisal of the role of coiled-coil structure in binding.
The observation that FgBP binds ligand more efficiently at lower temperatures has also been noted for some class $\mathrm{C} M$ proteins of group A streptococci. This in turn has been correlated with the stability of the $\alpha$-helical coiledcoil structure and a tendency for these proteins to unfold to random coil monomers at higher temperatures (Åkerström et al., 1992; Nilson et al., 1995; Cedervall et al., 1997). A similar explanation seems likely for FgBP since ongoing $\mathrm{CD}$ analysis has shown FgBP1 to become progressively more unfolded in response to increased temperature over the range $8-80{ }^{\circ} \mathrm{C}$ and to be about 0 , 16 and $30 \%$ unfolded at 8,37 and $45^{\circ} \mathrm{C}$, respectively (M. Meehan and others, unpublished data).

\section{ACKNOWLEDGEMENTS}

This work was supported by The National Pharmaceutical Biotechnology Centre, BioResearch Ireland, and by research grant SC/98/266 from Enterprise Ireland.

\section{REFERENCES}

Åkerstöm, B., Lindahl, G., Björck, L. \& Lindqvist, A. (1992). Protein Arp and protein $\mathrm{H}$ from group A streptococci. Ig binding and dimerization are regulated by temperature. J Immunol 148, 3238-3243.

Åkesson, P., Schmidt, K.-H., Cooney, J. \& Björck, L. (1994). M1 protein and protein $\mathrm{H}$ : IgGFc- and albumin-binding streptococcal surface proteins encoded by adjacent genes. Biochem J 300, 877-886.

Boschwitz, J. S. \& Timoney, J. F. (1994a). Characterization of the antiphagocytic activity of equine fibrinogen for Streptococcus equi subsp. equi. Microb Pathog 17, 121-129.

Boschwitz, J. S. \& Timoney, J. F. (1994b). Inhibition of C3 deposition on Streptococcus equi subsp. equi by $\mathrm{M}$ protein: a mechanism for survival in equine blood. Infect Immun 62, 3515-3520.

Caffrey, P., McVeigh, T. \& Owen, P. (1988). Western immunoblotting. In Immunochemical and Molecular Genetic Analysis of Bacterial Pathogens, pp. 255-266. Edited by P. Owen \& T. J. Foster. Amsterdam: Elsevier.

Cedervall, T., Johansson, M. U. \& Åkerström, B. (1997). Coiledcoil structure of group A streptococcal $M$ proteins. Different temperature stability of class $\mathrm{A}$ and $\mathrm{C}$ proteins by hydrophobicnonhydrophobic amino acid substitutions at heptad positions a and d. Biochemistry 36, 4987-4994.

Courtney, H. S., Liu, S., Dale, J. B. \& Hasty, D. L. (1997). Conversion of serotype 24 of Streptococcus pyogenes to M serotypes 5 and 18: effect on resistance to phagocytosis and adhesion to host cells. Infect Immun 65, 2472-2474.

Doolittle, R. R. (1994). Fibrinogen and fibrin. In Hemostasis and Thrombosis, 3rd edn, pp. 491-513. Edited by A. Bloom, C. D. Forbes, D. P. Thomas \& E. Tuddenham. New York: Churchill Livingstone.

Dulley, J. R. \& Grieve, P.A. (1975). A simple technique for eliminating interference by detergents in the Lowry method of protein determination. Anal Biochem 64, 136-141.

Feliciello, I. \& Chinali, G. (1993). A modified alkaline lysis method for the preparation of highly purified plasmid DNA from Escherichia coli. Anal Biochem 212, 394-401.

Herrmann, M., Lai, Q. J., Albrecht, R. M., Mosher, D. F. \& Proctor, R. A. (1993). Adhesion of Staphylococcus aureus to surface-bound 
platelets: role of fibrinogen/fibrin and platelet integrins. J Infect Dis $\mathbf{1 6 7}, 312-322$.

Kehoe, M. A. (1994). Cell-wall-associated proteins in Grampositive bacteria. In Bacterial Cell Wall (New Comprehensive Biochemistry, vol. 27), pp. 217-261. Edited by J.-M. Ghuysen \& R. Hakenbeck. Amsterdam: Elsevier.

Laemmli, U. K. (1970). Cleavage of structural proteins during the assembly of the head of bacteriophage T4. Nature 227, 680-685.

Lau, S. Y. M., Taneja, A. K. \& Hodges, R. S. (1984). Synthesis of a model protein of defined secondary and quaternary structure. Effect of chain length on the stabilization and formation of twostranded $\alpha$-helical coiled-coils. J Biol Chem 259, 13253-13261.

Lech, K. \& Brent, R. (1997). Media preparation and bacteriological tools. In Current Protocols in Molecular Biology, pp. 1.1.1-1.1.6. Edited by F. M. Ausubel and others. New York: Wiley.

McDevitt, D., Nanavaty, T., House-Pompeo, K., Bell, E., Turner, N., McIntire, L., Foster, T. \& Höök, M. (1997). Characterization of the interaction between the Staphylococcus aureus clumping factor (ClfA) and fibrinogen. Eur J Biochem 247, 416-424.

Meehan, M., Nowlan, P. \& Owen, P. (1998a). Affinity purification and characterization of a fibrinogen-binding protein complex which protects mice against lethal challenge with Streptococcus equi subsp. equi. Microbiology 144, 993-1003.

Meehan, M., Nowlan, P. \& Owen, P. (1998b). A protective fibrinogen-binding protein of Streptococcus equi. In Abstracts of the 140th Ordinary Meeting of the Society for General Microbiology (Nottingham, UK), p. 74, P24.

Moreillon, P., Entenza, J. M., Francioli, P., McDevitt, D., Foster, T. J., François, P. \& Vaudaux, P. (1995). Role of Staphylococcus aureus coagulase and clumping factor in pathogenesis of experimental endocarditis. Infect Immun 63, 4738-4743.

Navarre, W. W. \& Schneewind, O. (1999). Surface proteins of Gram-positive bacteria and mechanisms of their targeting to the cell wall envelope. Microbiol Mol Biol Rev 63, 174-229.

Newell, D. G., McBride, B. W. \& Clark, S. A. (1988). Enzyme-linked immunosorbent assay for soluble antigens. In Making Monoclonals. A Practical Beginners Guide to the Production and Characterization of Monoclonal Antibodies against Bacteria and Viruses, pp. 37-39. Colindale: Public Health Laboratory Service.

Ní Eidhin, D., Perkins, S., François, P., Vaudaux, P., Höök, M. \& Foster, T. J. (1998). Clumping factor B (ClfB), a new surfacelocated fibrinogen-binding adhesin of Staphylococcus aureus. Mol Microbiol 30, 245-257.

Nilson, B. H. K., Frick, I.-M., Åkesson, P., Forsén, S., Björck, L., Åkerström, B. \& Wikström, M. (1995). Structure and stability of protein $\mathrm{H}$ and the M1 protein from Streptococcus pyogenes. Implications for other surface proteins of Gram-positive bacteria. Biochemistry 34, 13688-13698.

O'Connell, D. P., Nanavaty, T., McDevitt, D., Gurusiddappa, S., Höök, M. \& Foster, T. J. (1998). The fibrinogen-binding MSCRAMM (clumping factor) of Staphylococcus aureus has a $\mathrm{Ca}^{2+}$-dependent inhibitory site. J Biol Chem 273, 6821-6829.

Palma, M., Wade, D., Flock, M. \& Flock, J.-I. (1998). Multiple binding sites in the interaction between an extracellular fibrinogen-binding protein from Staphylococcus aureus and fibrinogen. J Biol Chem 273, 13177-13181.

Patti, J. M., Allen, B. L., McGavin, M. J. \& Höök, M. (1994). MSCRAMM-mediated adherence of microorganisms to host tissues. Annu Rev Microbiol 48, 585-617.
Poirier, T. P., Kehoe, M. A., Whitnack, E., Dockter, M. E. \& Beachey, E. H. (1989). Fibrinogen binding and resistance to phagocytosis of Streptococcus sanguis expressing cloned $\mathrm{M}$ protein of Streptococcus pyogenes. Infect Immun 57, 29-35.

Provencher, S. W. \& Glockner, J. (1981). Estimation of globular protein secondary structure from circular dichroism. Biochemistry 20, 33-37.

Reichardt, W., Schmidt, K.-H., Amberg, C. \& Gubbe, K. (1997). Mapping of binding sites for human serum albumin and fibrinogen on the M3-protein. Molecular model and function in the pathogenic mechanism. In Streptococci and the Host, pp. 577-579. Edited by T. Horaud, A. Bouvet, R. Leclercq, H. de Montclos \& M. Sicard. New York: Plenum.

Sambrook, J., Fritsch, E. F. \& Maniatis, T. (1989). Molecular Cloning: a Laboratory Manual, 2nd edn. Cold Spring Harbor, NY : Cold Spring Harbor Laboratory.

Schleifer, K. H. \& Kandler, O. (1972). Peptidoglycan types of bacterial cell walls and their taxonomic implications. Bacteriol Rev 36, 407-477.

Su, J. Y., Hodges, R. S. \& Kay, C. M. (1994). Effect of chain length on the formation and stability of synthetic alpha-helical coiled coils. Biochemistry 33, 15501-15510.

Talay, S. R., Grammel, M. P. \& Chhatwal, G. S. (1996). Structure of a group $C$ streptococcal protein that binds to fibrinogen, albumin and immunoglobulin $G$ via overlapping modules. Biochem J 315, 577-582.

Timoney, J. F. (1993). Strangles. Vet Clin N Am Equine Pract 9, 365-374.

Timoney, J. F., Artiushin, S. C. \& Boschwitz, J. S. (1997). Comparison of the sequences and functions of Streptococcus equi Mlike proteins SeM and SzPSe. Infect Immun 65, 3600-3605.

Ton-That, H., Faull, K. F. \& Schneewind, O. (1997). Anchor structure of staphylococcal surface proteins. A branched peptide that links the carboxyl terminus of proteins to the cell wall. J Biol Chem 272, 22285-22292.

Vaudaux, P., Pittet, D., Haeberli, A., Huggler, E., Nydegger, U. E., Lew, D. P. \& Waldvogel, F. A. (1989). Host factors selectively increase staphylococcal adherence on inserted catheters: a role for fibronectin and fibrinogen or fibrin. J Infect Dis 160, 865-875.

Vaudaux, P. E., François, P., Proctor, R. A., McDevitt, D., Foster, T. J., Albrecht, R. M., Lew, D. P., Wabers, H. \& Cooper, S. L. (1995). Use of adhesion-defective mutants of Staphylococcus aureus to define the role of specific plasma proteins in promoting bacterial adhesion to canine arteriovenous shunts. Infect Immun 63, 585-590.

Whitnack, E. \& Beachey, E. H. (1982). Anti-opsonic activity of fibrinogen bound to $M$ protein on the surface of group $A$ streptococci. J Clin Invest 69, 1042-1045.

Whitnack, E. \& Beachey, E. H. (1985). Biochemical and biological properties of the binding of human fibrinogen to $M$ protein in group A streptococci. J Bacteriol 164, 350-358.

Yu, C.-E. \& Ferretti, J. J. (1989). Molecular epidemiologic analysis of the type A streptococcal exotoxin (erythrogenic toxin) gene (speA) in clinical Streptococcus pyogenes strains. Infect Immun 57, 3715-3719.

Received 18 November 1999; revised 31 January 2000; accepted 8 February 2000. 